\title{
CARACTERIZAÇÃO DE AMOSTRAS COMERCIAIS DE VERMICOMPOSTO DE ESTERCO BOVINO E AVALIAÇÃO DA INFLUÊNCIA DO pH E DO TEMPO NA ADSORÇÃO DE Co(II), Zn(II) AND Cu(II)
}

João da Paixão Soares e Jovino Araújo de Souza

Departamento de Química, Universidade Federal de São Carlos, CP 676, 13565-905 São Carlos - SP

Éder Tadeu Gomes Cavalheiro*

Departamento de Química e Física Molecular, Instituto de Química de São Carlos, Universidade de São Paulo, CP 780, 13560-970 São Carlos - SP

Recebido em 25/6/02; aceito em 9/9/03

\begin{abstract}
CHARACTERIZATION OF COMMERCIAL SAMPLES OF VERMICOMPOST FROM BOVINE MANURE AND EVALUATION OF THE INFLUENCE OF pH AND TIME ON Co(II), Zn(II) and Cu(II) ADSORPTION. Some commercial samples of vermicompost from bovine manure (humus) were characterized by thermogravimetry with respect to humidity, organic matter and ash contents, the percentages of which range from 6.55 to $5.35 \%, 53.01$ to $69.96 \%$ and 46.44 to $66,14 \%$, respectively. The capacity of adsorption of $\mathrm{Cu}^{2+}, \mathrm{Zn}^{2+}$ and $\mathrm{Co}^{2+}$ ions by these samples has been evaluated as a function of $\mathrm{pH}$ and time. The contents of several metal ions in the original vermicompost samples have been determined by flame atomic absorption spectrometry after digestion in a microwave oven. The high nitrogen content suggests that the earthworms used in the maturation procedure lead to an efficient degradation of organic matter. The metal retention was affected by both $\mathrm{pH}$ and adsorption time. The results also show that adsorption follows the order $\mathrm{Cu}^{2+}>\mathrm{Zn}^{2+}>\mathrm{Co}^{2+}$.
\end{abstract}

Keywords: vermicompost; thermogravimetry; metal ion adsorption.

\section{INTRODUÇÃO}

Com a crescente adoção das várias formas de plantio direto nos trópicos, inclusive no Brasil, com elevado uso de adubos, herbicidas e outros insumos, o papel da vermicompostagem pode ser considerado importante quanto aos aspectos físicos e biológicos desses sistemas produtivos, pois pode adsorver e de certa maneira "controlar" a presença destes aditivos agrícolas no meio ambiente ${ }^{1}$.

Segundo Sensi ${ }^{2}$, a vermicompostagem é geralmente definida como degradação e estabilização biológica da matéria orgânica após a ingestão destes resíduos por minhocas, sendo a espécie Eisenia foetida a mais utilizada. O produto da vermicompostagem é o vermicomposto, um adubo orgânico obtido a partir do esterco de animais, previamente estabilizado e neutro, ou a partir de compostos vegetais.

Pela ação das minhocas o material bruto é transformado em adubo, rico em microorganismos, substâncias húmicas, fixadores de nitrogênio atmosférico e bactérias fixadoras de potássio, fósforo, ferro e outros minerais, que são indispensáveis às plantas. O vermicomposto é rico em matéria orgânica e reconstitui a estrutura física e biológica do solo. Atuando como fertilizante natural, o vermicomposto neutraliza o pH do solo e eleva a concentração de nutrientes, aumentando a resistência das plantas contra pragas e doenças ${ }^{3}$.

Em decorrência, pode diminuir a necessidade da adubação química e o uso de agrotóxicos. O vermicomposto pode conter quantidades apreciáveis de metais pesados tóxicos, tais como cádmio, cobre, níquel, chumbo e outros, devido ao seu caráter adsorvente para íons metálicos ${ }^{4}$. O incremento na concentração destes metais no meio ambiente vem causando efeitos nocivos à saúde humana, à flora e à fauna, por alteração do ciclo global desses metais. Assim, o uso des-

*e-mail: cavalheiro@iqsc.usp.br tes fertilizantes deve ser feito tomando-se o cuidado de avaliar a concentração de íons metálicos presentes, evitando-se a contaminação de recursos naturais ${ }^{5-8}$.

Quanto aos metais investigados neste trabalho, quando de sua adsorção nas amostras de vermicomposto, o cobre encontra-se, no solo, quase que exclusivamente na forma divalente $\mathrm{Cu}$ (II), aparecendo em maior proporção adsorvido aos minerais de argila, aos hidróxidos de ferro e complexado com a matéria orgânica. Essas formas adsorvidas e complexadas controlam a concentração desse metal na matriz do solo, sendo que a totalidade do cobre solúvel está na forma de complexos com a matéria orgânica em solos ácidos ${ }^{9,10}$.

Em relação ao zinco, o principal fator que influencia sua disponibilidade é a adsorção por substâncias originalmente presentes no solo ou corpos d'água que, conseqüentemente, controlam sua concentração nestes sistemas. Normalmente, a capacidade que o solo apresenta em adsorver este elemento é muito maior do que a quantidade usada em adubos. A adsorção, fixação e precipitação do zinco adicionado ao solo dependem de minerais como argila, óxidos hidratados, carbonatos e matéria orgânica ${ }^{11}$. Já o cobalto se acumula nas regiões mais ricas em matéria orgânica, o que sugere uma fixação do elemento pelo húmus. Além disso, os óxidos de ferro têm grande afinidade para adsorver cobalto, o que pode causar correlação positiva entre ferro e cobalto ${ }^{12}$.

Para a determinação destes metais nas amostras de vermicomposto, torna-se necessária sua solubilização. $\mathrm{O}$ tratamento de amostras para a dissolução mediante o aquecimento com microondas tem demonstrado ser um processo mais rápido e eficiente em comparação ao aquecimento convencional. Além disso, o uso desta tecnologia reduz riscos para os seres humanos e o meio ambiente, uma vez que são utilizados menores volumes de reagentes e os sistemas fechados reduzem riscos de acidentes ${ }^{12}$. Além destas vantagens, as digestões de amostra feitas por microondas permitem a dissolução em altas temperaturas e a redução de perda de analitos por volatilização ${ }^{12}$. 
A determinação de umidade, matéria orgânica e voláteis desprendidos de materiais inorgânicos, como por exemplo $\mathrm{CO}_{2}$ de carbonatos, e cinzas é importante na caracterização de diversos materiais. A termogravimetria é a técnica termoanalítica que acompanha a variação de massa de uma amostra, enquanto é submetida a uma programação de temperatura. $\mathrm{O}$ experimento é realizado sob atmosfera controlada, em um equipamento conhecido como termobalança ${ }^{13,14}$. Seu uso na determinação dos parâmetros acima é vantajoso, no sentido de que é possível obter todas estas informações com apenas uma análise e usando massas de amostra pequenas. A alternância de atmosfera inerte, seguida de atmosfera oxidante no interior do forno, pode levar à determinação do carvão formado nas decomposições ${ }^{13}$.

No presente trabalho foram abordados alguns aspectos referentes aos vermicompostos adquiridos no comércio e usados como fertilizantes. Inicialmente, foi feita uma caracterização físico-química quanto ao $\mathrm{pH}$ e teores de $\mathrm{C}, \mathrm{N}, \mathrm{P}$ e S. Também investigou-se o uso do forno de microondas na solubilização destas amostras, para posterior determinação da presença de diversos metais e para avaliar se estes já não contém metais adsorvidos antes de sua utilização.

Em adição a termogravimetria foi usada para determinar teores de umidade, matéria orgânica/voláteis e cinzas. Avaliou-se também a influência do $\mathrm{pH}$ e do tempo na absorção dos íons metálicos $\mathrm{Cu}^{2+}$, $\mathrm{Zn}^{2+} \mathrm{e} \mathrm{Co}^{2+}$ pelas amostras de vermicompostos de origem comercial, já que informações a respeito da adsorção de metais por vermicompostos podem ser usadas para prever eventuais impactos ambientais causados pelo uso destes fertilizantes.

\section{PARTE EXPERIMENTAL}

Todas as soluções utilizadas neste trabalho foram preparadas com água bidestilada em destilador de quartzo (TE-178, Tecnal) e reagentes de grau analítico (P.A.), salvo os casos especificados abaixo. Todas as determinações foram feitas em triplicata, exceto aquelas relativas à caracterização físico-química das amostras de vermicomposto.

\section{Preparação das amostras}

As quatro amostras de vermicomposto, produzidas com minhocas vermelhas da Califórnia (Eisenia foetida), foram adquiridas no comércio, na região de São Carlos/SP. Antes da caracterização, aproximadamente $500 \mathrm{~g}$ de cada amostra foram secas ao ar, por $24 \mathrm{~h}$, em bandejas plásticas de $15 \times 30 \mathrm{~cm}$, resultando em uma coluna de aproximadamente $2 \mathrm{~cm}$ do vermicomposto, em cada caso.

Após a secagem, as amostras foram trituradas em moinho de facas (TE 631, Tecnal) a 15 rpm durante 20 min, para maior homogeneização. Após a moagem, as amostras foram novamente espalhadas nas bandejas plásticas de 15 x $30 \mathrm{~cm}$ e coletadas três porções de $100 \mathrm{mg}$ no centro e em cada lado das bandejas, para cada amostra.

A solubilização das amostras foi efetuada utilizando-se um forno de microondas com sistema fechado (ETHOS-1600, Milestone), equipado com frascos de teflon com tampa (ETHOS - 1600 MEGA, Milestone). Os frascos foram previamente descontaminados com solução de $\mathrm{HNO}_{3} 10 \%$ (v/v), por $24 \mathrm{~h}$. A solução ácida foi drenada e os frascos, preenchidos com água purificada em sistema Mili-Q. Pesou-se $100 \mathrm{mg}$ de cada amostra previamente moída, as quais foram transferidas para os frascos de teflon.

Inicialmente tentou-se solubilizar as amostras apenas com água régia, entretanto não houve dissolução completa das mesmas. Resultados satisfatórios foram obtidos usando-se uma mistura de 2,0 mL de ácido HF $48 \%(\mathrm{~m} / \mathrm{m})$ e 5,0 $\mathrm{mL}$ de água régia, devido à presença de compostos inorgânicos na amostra.
As amostras foram submetidas a vários programas de aquecimento, variando-se o tempo de exposição e a potência aplicada, na presença das misturas ácidas.

Após os ciclos de aquecimento, os frascos de teflon foram resfriados e as amostras diluídas em água purificada em sistema Mili-Q suficiente para 100,0 mL de solução. Foram tomadas três porções para cada amostra, as quais foram analisadas em triplicata, totalizando nove dissoluções para cada amostra. Também foram preparadas triplicadas das soluções para ensaios em branco.

\section{Composição elementar}

As percentagens em peso de $\mathrm{C}, \mathrm{N}$, e $\mathrm{S}$ nas amostras foram determinadas em analisador de CHNS-O (EA 1108, Fisions), usando condutividade térmica para $\mathrm{N}$ e combustão secundária para $\mathrm{S}^{1}$. Os teores de fósforo foram obtidos pelo método espectrofotométrico do molibdato de amônio, de acordo com o procedimento em fluxo descrito por Reis et al. ${ }^{15}$.

\section{Determinação do $\mathrm{pH}^{3}$}

Transferiu-se $10,0 \mathrm{~g}$ do vermicomposto para béquer de $100 \mathrm{~mL}$ e adicionou-se $25,0 \mathrm{~mL}$ de solução de $\mathrm{CaCl}_{2} 0,01 \mathrm{~mol} \mathrm{~L}^{-1}$, agitandose com bastão de vidro. Aguardou-se por 15 min para hidratação completa da amostra. Agitou-se por $5 \mathrm{~min}$ em mesa agitadora, na temperatura ambiente, medindo-se em seguida o $\mathrm{pH}$ em triplicata, utilizando medidor de $\mathrm{pH}$ Cornin-430, equipado com eletrodo combinado de vidro (DME CV-1, Digimed).

\section{Medidas termogravimétricas}

Foram realizadas em um módulo termogravimétrico TGA 2050, acoplado a um termoanalisador TA 2000 (TA Instruments), usando suporte de amostra de alumina, sob atmosfera dinâmica de nitrogênio e ar sintético (vazão de $90 \mathrm{~mL} \mathrm{~min}^{-1}$ ), sob razão de aquecimento de $20{ }^{\circ} \mathrm{C} \mathrm{min}^{-1}$ e massas de amostra em torno de $7 \mathrm{mg}$.

\section{Determinação da concentração de metais}

Nas amostras dissolvidas no forno de microondas foram determinadas as concentrações $\left(\mathrm{mg} \mathrm{kg}^{-1}\right)$ dos metais $\mathrm{Fe}, \mathrm{Al}, \mathrm{K}, \mathrm{Mg}, \mathrm{Ca}$, $\mathrm{Zn}, \mathrm{Cu}, \mathrm{Cr}, \mathrm{Co}, \mathrm{Pb}, \mathrm{Cd}, \mathrm{Mn}$, os quais foram escolhidos devido à sua importância como macro e micro nutrientes ou por serem considerados potencialmente contaminantes ambientais.

Para a determinação da concentração de cada um destes metais nas amostras de vermicomposto foi utilizado espectrofotômetro de absorção atômica com atomização por chama (GEMNI-AA 12/1475, INTRALAB).

\section{Influência do pH na adsorção dos íons $\mathrm{Cu}^{2+}, \mathrm{Zn}^{2+} \mathrm{e} \mathrm{Co}^{2+}$}

Foram pesadas 72 frações de $0,250 \mathrm{~g}$ (8 para cada metal em triplicata) da amostra 4, que foram transferidas para bequeres de 250 $\mathrm{mL}$, adicionando-se à cada recipiente $50 \mathrm{~mL}$ de solução $500 \mathrm{mg} \mathrm{L}^{-1}$ de $\mathrm{CuSO}_{4}, \mathrm{ZnCl}_{2}$ ou $\mathrm{CoCl}_{2}$, obtidas à partir de soluções-estoque $1000 \mathrm{mg} \mathrm{L}^{-1}$. Ajustou-se o pH para 2,0; 3,0; 4,0; 5,0; 6,0; 7,0; 8,0 e 9,0 com solução $0,10 \mathrm{~mol} \mathrm{~L}^{-1}$ de $\mathrm{NaOH}$ ou $\mathrm{HCl}$, conforme o caso.

As misturas foram agitadas por $24 \mathrm{~h}$. Em seguida, filtraram-se as amostras em papel de filtro qualitativo, determinando-se então a concentração restante dos íons metálicos nas soluções, por espectrofotometria de absorção atômica. As quantidades dos íons adsorvidos foram determinadas por diferença entre a quantidade adicionada inicialmente e a presente na solução após o tempo de agitação considerado. 
Influência do tempo na adsorção dos íons $\mathrm{Cu}^{2+}, \mathrm{Zn}^{2+} \mathrm{e} \mathrm{Co}^{2+}$

Foram pesadas 27 frações (9 para cada metal) de $0,2500 \mathrm{~g}$ da amostra 4, que foram transferidas para bequeres de $250,0 \mathrm{~mL}$, adicionando-se a cada recipiente $50,0 \mathrm{~mL}$ de solução $500 \mathrm{mg} \mathrm{L}^{-1} \mathrm{de} \mathrm{CuSO}_{4}$, $\mathrm{ZnCl}_{2}$ ou $\mathrm{CoCl}_{2}$, obtidas a partir de soluções-estoque $1000 \mathrm{mg} \mathrm{L}^{-1}$. Ajustou-se o pH para 7,0 com solução de $\mathrm{NaOH} 0,10 \mathrm{~mol} \mathrm{~L}^{-1}$. As soluções foram colocadas sob agitação e a concentração de equilíbrio determinada por espectrofotometria de absorção atômica após $3,6,9,12,15,18,20,22$ e $24 \mathrm{~h}$. As quantidades dos íons adsorvidos foram determinadas por diferença entre a quantidade adicionada inicialmente e a presente na solução após o tempo de agitação considerado.

\section{RESULTADOS E DISCUSSÃO}

\section{Caracterização das amostras de vermicomposto}

Os resultados obtidos na caracterização físico-química dos vermicompostos são apresentados na Tabela 1 .

Todas as amostras de vermicomposto apresentaram $\mathrm{pH}$ em torno de 6 , em solução de $\mathrm{CaCl}_{2}$ 1,0 $\mathrm{mol} \mathrm{L}^{-1}$. Segundo a literatura isto é decorrente dos processos digestivos efetuados pelas minhocas ${ }^{4}$. O valor de $\mathrm{pH}$ próximo da neutralidade sugere que o vermicomposto, uma vez adicionado ao solo, poderá apresentar ação corretiva da sua acidez, devido à sua propriedade tamponante. Constatações semelhantes foram descritas por Tsai e Tablas ${ }^{16}$.

A Tabela 1 também apresenta a composição dos vermicompostos analisados quanto aos teores de C, N, S e P. Alguns pesquisadores têm utilizado a relação $\mathrm{C} / \mathrm{N}$ para evidenciar o grau de humificação das substâncias húmicas ${ }^{17-19}$, o qual se relaciona com o grau de estabilização da matéria orgânica no mesmo ${ }^{17}$. Lamin et al. ${ }^{5}$ consideram que quando a relação $\mathrm{C} / \mathrm{N}$ for maior que 30 , a decomposição da matéria prima é lenta. Entretanto, para valores de $\mathrm{C} / \mathrm{N}$ compreendidos entre 30 e 20 a decomposição é considerada satisfatória, e total para valores abaixo de $20^{9}$.

No presente estudo, os valores encontrados para a relação $\mathrm{C} / \mathrm{N}$ variaram de 9,02 a 13,74\% (Tabela 1). Isto indica que os resíduos orgânicos foram totalmente decompostos, de acordo com os critérios acima apresentados.

Em estudos recentes, realizados em solo, percentagens de nitrogênio total da ordem de $0,14 \%$ foram descritas ${ }^{19}$. No presente trabalho, as percentagens de nitrogênio no húmus comercial variaram de 0,92 a $2,92 \%$, acima do observado em solos, evidenciando que as minhocas apresentam em seu metabolismo a capacidade de promover uma degradação eficiente do material original, concentrando os nutrientes nitrogenados e devolvendo-os ao solo ${ }^{4}$. As diferenças entre os valores de fósforo e enxofre das amostras 1 a 4 são pequenas, demonstrando que as mesmas passaram por processo de humificação semelhante. As concentrações de nitrogênio, enxofre e fósforo nos vermicompostos sugerem que estes materiais poderiam ser usados como fertilizantes, mas outros estudos são necessários.

Os resultados de umidade, matéria orgânica total e cinzas foram determinados por termogravimetria, a qual é proposta aqui como uma alternativa para a caracterização de vermicompostos. Os resultados obtidos são apresentados na Tabela 1.

\section{Resultados termogravimétricos}

A Figura 1 apresenta o perfil termogravimétrico típico obtido para a amostra 1, como referência, sob atmosfera dinâmica de ar e nitrogênio a uma vazão constante de $90 \mathrm{~mL} \mathrm{~min}^{-1}$. De maneira geral, pode-se observar em todas as curvas TG duas etapas de perda de
Tabela 1. Características físico-químicas das amostras de vermicomposto

\begin{tabular}{lcccc}
\hline Parâmetro & \multicolumn{4}{c}{ Valores obtidos } \\
& Amostra 1 & Amostra 2 & Amostra 3 & Amostra 4 \\
\hline $\mathrm{pH}$ & 6,20 & 6,15 & 6,19 & 6,15 \\
$\mathrm{C}(\%)$ & 20,57 & 14,12 & 12,64 & 33,95 \\
$\mathrm{~N}(\%)$ & 2,28 & 1,20 & 0,92 & 2,92 \\
$\mathrm{~S}(\%)$ & 3,30 & 3,02 & 2,98 & 4,14 \\
$\mathrm{P}(\%)$ & 1,18 & 1,15 & 1,00 & 1,20 \\
Relação C/N & 9,02 & 11,77 & 13,74 & 11,63 \\
Umidade (\%) & 6,55 & 3,82 & 4,22 & 5,35 \\
Cinzas (\%) & 53,01 & 69,96 & 60,57 & 58,40 \\
Orgânicos e & 46,44 & 66,14 & 56,35 & 53,05 \\
voláteis (\%) & & & & \\
\hline
\end{tabular}

massa, sob ambas atmosferas, representadas pelas regiões I e II, na Figura 1. A razão de $20{ }^{\circ} \mathrm{C} \mathrm{min}{ }^{-1}$ foi utilizada para reduzir o tempo de análise, sem alteração nos resultados quantitativos e no perfil das curvas TG, de acordo com os testes utilizados.

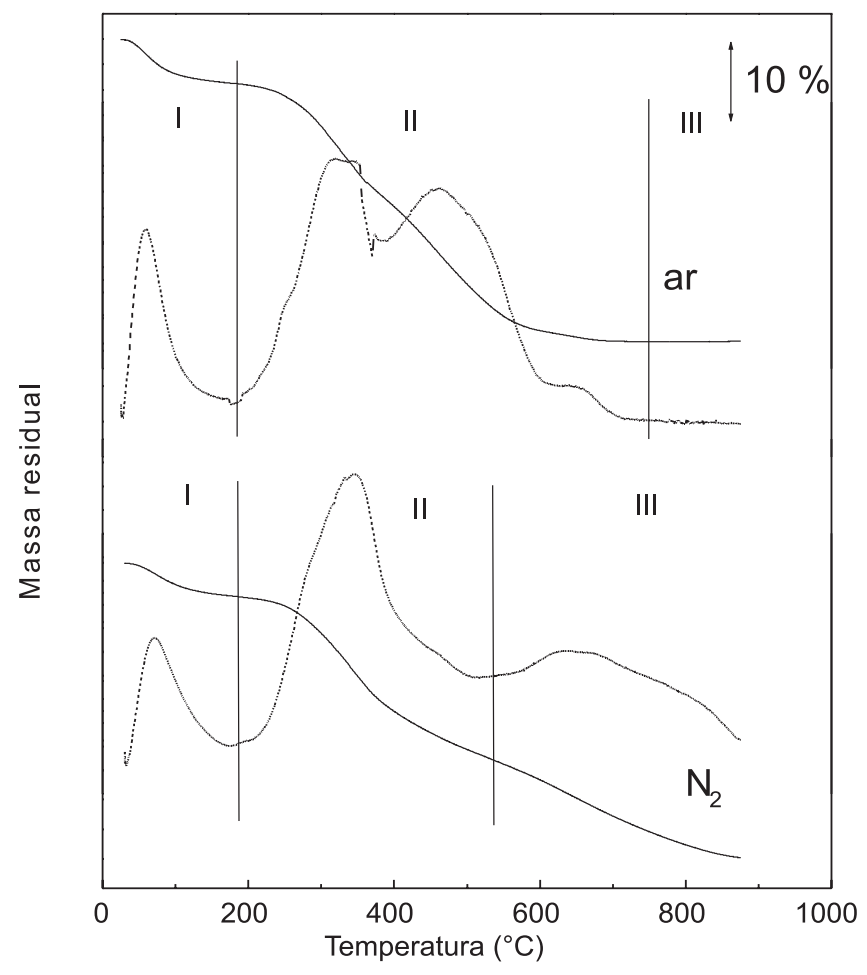

Figura 1. Curvas termogravimétricas da amostra 1 obtidas sob atmosferas

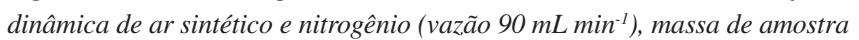
em torno de $7 \mathrm{mg}$, suporte de amostra de alumina e razão de aquecimento de $20^{\circ} \mathrm{C} \mathrm{min}^{-1}$

Sob ar, a primeira etapa estende-se desde o início do experimento até $170-180^{\circ} \mathrm{C}$, correspondendo à perda de água. A segunda etapa vai de $170-180{ }^{\circ} \mathrm{C}$ até $700-750^{\circ} \mathrm{C}$, correspondendo à decomposição da matéria orgânica e liberação de substâncias voláteis provenientes da decomposição de compostos inorgânicos. Os dois processos se sobrepõem e a determinação do final da desidratação pode ser melhor definida com auxílio da curva DTG, como indicado na Figura 1. Nesta figura, as barras paralelas ao eixo das ordenadas apresentam as temperaturas escolhidas para definir o início e o final dos eventos térmicos sob ar. 
Para caracterização dos gases envolvidos na decomposição seria necessário utilizar técnicas de detecção e separação simultâneas ao experimento TG, o que não é possível no equipamento aqui utilizado.

Sob nitrogênio, observa-se a etapa de desidratação no mesmo intervalo de temperatura descrito anteriormente, porém, a natureza inerte desta atmosfera impede a oxidação da matéria orgânica, que se decompõe lentamente até próximo a $900{ }^{\circ} \mathrm{C}$. O fato desta decomposição não se completar implica em que o uso de nitrogênio não é adequado em tais determinações, como já era esperado, gerando resíduo carbonizado (região III - Figura 1).

Usando a termogravimetria, sob ar, obtiveram-se valores médios de 4,98 e 55,6\% para os teores de umidade, assim como matéria orgânica e voláteis (gases libertados na decomposição de substâncias inorgânicas), respectivamente. É interessante observar que os teores de resíduo (cinzas, região III - Figura 1), obtidos em cada caso e apresentados na Tabela 1, variaram de 53,01 a 69,96\% (média $61,51 \%$ ). Estes valores elevados sugerem que a agregação de solo ao esterco é feita em quantidade significativa. Se este solo estiver contaminado, poderá haver a incorporação de metais pesados ao húmus resultante.

Recentemente, Pereira e Arruda ${ }^{20}$ apresentaram curvas TG para avaliar vermicompostos, mas não fazem menção às vantagens do uso da curva DTG, nem do efeito da atmosfera nestes experimentos.

\section{Determinação de metais nas amostras}

Foram escolhidos elementos essenciais e alguns metais pesados que poderiam estar presentes no húmus, como contaminantes. $\mathrm{Na}$ Tabela 2 são apresentados os metais analisados e os resultados obtidos para cada caso, usando espectrofotometria de absorção atômica por chama, das amostras solubilizadas em forno de microondas.

Tabela 2. Concentração de metais nas amostras de vermicompostos comerciais estudados

\begin{tabular}{lcccc}
\hline Metais & \multicolumn{4}{c}{ Concentração $\left(\mathrm{mg} \mathrm{kg}^{-1} \pm \mathrm{DV}\right)^{\mathrm{a}}$} \\
& Amostra 1 & Amostra 2 & Amostra 3 & Amostra 4 \\
\hline $\mathrm{Fe}$ & $98,0 \pm 0,2$ & $271 \pm 0,1$ & $1700 \pm 0,5$ & $353 \pm 0,8$ \\
$\mathrm{Al}$ & $62,4 \pm 0,1$ & $75,1 \pm 0,3$ & $79,8 \pm 0,9$ & $46,2 \pm 0,2$ \\
$\mathrm{~K}$ & $59,8 \pm 0,1$ & $20,6 \pm 0,8$ & $104 \pm 0,3$ & $83,8 \pm 0,7$ \\
$\mathrm{Mg}$ & $84,1 \pm 0,1$ & $24,1 \pm 0,9$ & $12,8 \pm 0,7$ & $55,1 \pm 0,9$ \\
$\mathrm{Ca}$ & $116 \pm 0,8$ & $299 \pm 0,3$ & $75,0 \pm 0,8$ & $85,1 \pm 0,5$ \\
\hline
\end{tabular}

${ }^{a}$ Média de três repetições \pm desvio padrão

Resultados adequados foram obtidos usando mistura de água régia e ácido fluorídrico e um programa de aquecimento em três etapas: etapa 1: $5 \mathrm{~min}, 250 \mathrm{~W}$; etapa 2: $3 \mathrm{~min}, 600 \mathrm{~W}$ e etapa 3: $5 \mathrm{~min}$ de ventilação.

As concentrações de metais pesados das amostras, Tabela 2, encontraram-se abaixo dos valores máximos normalmente encontrados em solos ${ }^{21}$ e, portanto, as amostras de húmus adquiridas no comércio e avaliadas neste trabalho não apresentaram risco de contaminação ambiental.

Nas análises realizadas não foi possível detectar $\mathrm{Cu}, \mathrm{Co}, \mathrm{Cd}, \mathrm{Cr}$, $\mathrm{Pb}, \mathrm{Mn}$ e $\mathrm{Zn}$ nos vermicompostos.

A concentração relativamente alta de ferro presente na amostra 3 (Tabela 2), é devida, provavelmente, à presença de minerais que contém esse elemento, como hematita $\left(\alpha-\mathrm{Fe}_{2} \mathrm{O}_{3}\right)$ e goethita $(\alpha-\mathrm{FeOOH})^{19}$, ocasionalmente presentes no solo e incorporados durante a preparação do húmus.
A baixa relação $\mathrm{C} / \mathrm{N}$ encontrada, que sugere a decomposição completa da matéria orgânica, discutida anteriormente, pode estar relacionada com a alta concentração dos macro e micronutrientes encontrada, por exemplo para $\mathrm{Ca}$ e $\mathrm{Mg}$ que, nas amostras de vermicomposto, variaram de 75 a 299 e de 12,8 a $84,1 \mathrm{mg} \mathrm{kg}^{-1}$, respectivamente, além do $\mathrm{pH}$ próximo ao neutro.

\section{Influência do pH na adsorção dos íons $\mathrm{Cu}^{2+}, \mathrm{Zn}^{2+} \mathrm{e} \mathrm{Co}^{2+}$}

Foram realizados experimentos de adsorção em diferentes valores de $\mathrm{pH}$ para definir a capacidade do vermicomposto em adsorver estes metais. A Figura 2 apresenta a percentagem da adsorção dos íons $\mathrm{Cu}^{2+}, \mathrm{Zn}^{2+}$ e $\mathrm{Co}^{2+}$, em função do $\mathrm{pH}$, após $24 \mathrm{~h}$ sob agitação. Como pode ser observado, ocorreu baixa adsorção de cobalto para valores $\mathrm{pH}$ menores que 5 , sugerindo que a protonação das substâncias húmicas presentes no vermicomposto dificulta sua interação com o metal. A partir de pH 6 houve um aumento na adsorção até pH 9.

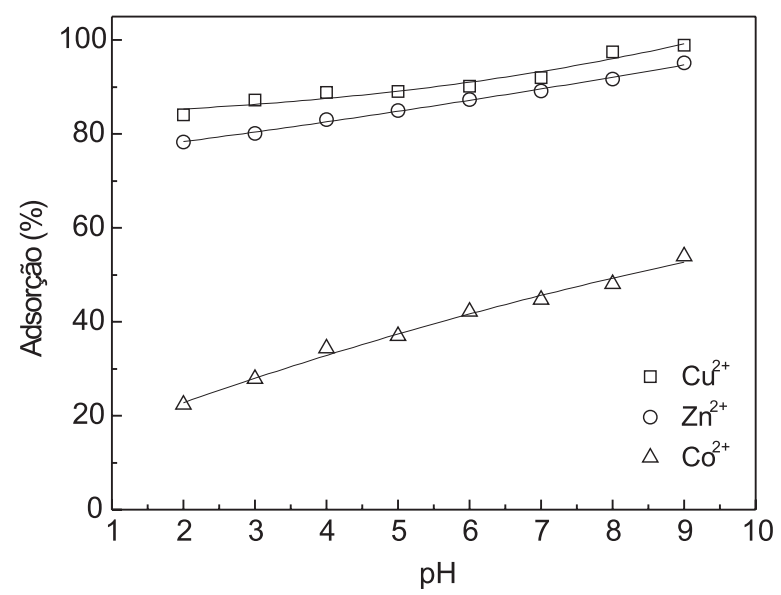

Figura 2. Adsorção dos íons $\mathrm{Cu}^{2+}, \mathrm{Zn}^{2+}$ e $\mathrm{Co}^{2+}$ em vermicomposto, em função do $\mathrm{pH}$

Dentre os íons investigados, o $\mathrm{Cu}^{2+}$, considerado micronutriente, foi o que mais se adsorveu. A adsorção, nas condições especificadas, foi de $99 \mathrm{mg} \mathrm{g}^{-1}$ (97\%). O alto teor de cobre adsorvido ajuda a entender porque, em solos ricos em matéria orgânica, são necessárias doses mais elevadas deste elemento na adubação. O cobre presente em solo tende a persistir no mesmo, sendo fixado fortemente pela matéria orgânica, por óxidos de $\mathrm{Fe}, \mathrm{Al}$ e Mn e pelos minerais de argila. Além disso, o ácido húmico apresenta forte interação com os íons $\mathrm{Cu}^{2+}$, o que facilita a adsorção ${ }^{21}$.

Usando os valores de $\mathrm{K}_{\mathrm{ps}}=1,3 \cdot 10^{-15}, 2,0 \cdot 10^{-17}$ e $2,2 \cdot 10^{-20}$, respectivamente para os hidróxidos ${ }^{22} \mathrm{de} \mathrm{Co}^{2+}, \mathrm{Zn}^{2+} \mathrm{e} \mathrm{Cu}^{2+} \mathrm{e}$, considerando as concentrações molares referentes a $500 \mathrm{mg} \mathrm{L}^{-1}$ para cada íon, os valores de $\mathrm{pH}$ nos quais haveria precipitação dos hidróxidos seriam 7,6; 6,7 e 5,22, respectivamente, para $\mathrm{Co}(\mathrm{OH})_{2}, \mathrm{Zn}(\mathrm{OH})_{2}$ e $\mathrm{Cu}(\mathrm{OH})_{2}$. Caso ocorresse precipitação, seria esperada uma variação brusca nas curvas de adsorção da Figura 2. Entretanto, um desvio da variação foi observado apenas para o $\mathrm{Cu}^{2+}$, em $\mathrm{pH}$ acima de 7. Isto indica que deve haver forte interação entre os cátions e o húmus, o que previne sua precipitação na forma de hidróxidos.

$\mathrm{O}$ íon $\mathrm{Zn}^{2+}$ foi adsorvido mais fortemente que o $\mathrm{Co}^{2+}$. A adsorção máxima do zinco foi de $95 \%$ e a de cobalto, $58 \%$. A capacidade do solo para adsorver o elemento zinco é muito maior que a quantidade usada em adubos e, uma vez adsorvido, não fica sujeita à lixiviação ${ }^{10}$. A menor adsorção de cobalto deve ser atribuída, provavelmente, à menor afinidade deste elemento pelo substrato. 
Os íons $\mathrm{Cu}^{2+}$ e $\mathrm{Zn}^{2+}$ apresentaram elevada afinidade pelos grupos ativos de adsorção do vermicomposto. O cobre foi encontrado em concentrações basais maiores que as dos íons $\mathrm{Zn}^{2+} \mathrm{e} \mathrm{Co}^{2+}$ na amostra 4, a qual foi escolhida para o estudo do processo de adsorção (Tabela 2).

\section{Influência do tempo na adsorção dos íons $\mathrm{Cu}^{2+}, \mathrm{Zn}^{2+}$ e $\mathrm{Co}^{2+}$}

Foram realizados experimentos de adsorção em função do tempo em pH 7, com a concentração inicial de $500 \mathrm{mg} \mathrm{L}^{-1}$ para os íons $\mathrm{Cu}$ (II), Co(II) e $\mathrm{Zn}$ (II). A velocidade de adsorção de metais pesados em solução depende de vários fatores, sendo os mais importantes o tamanho das partículas do adsorvente, a estrutura das moléculas adsorvidas e a natureza e porosidade do adsorvente. A Figura 3 apresenta o efeito do tempo na adsorção destes íons.

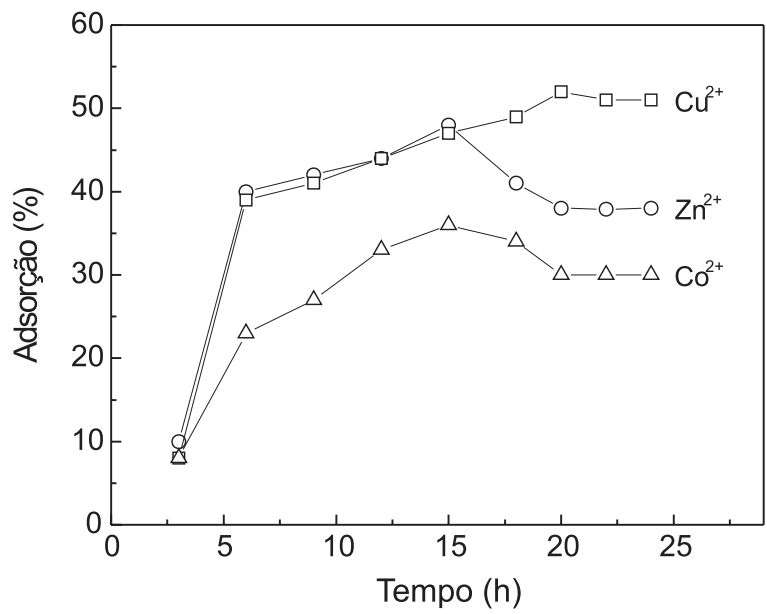

Figura 3. Adsorção dos íons $\mathrm{Cu}^{2+}, \mathrm{Zn}^{2+} e \mathrm{Co}^{2+}$ em vermicomposto, em função do tempo em $\mathrm{pH} 7$

As adsorções dos íons $\mathrm{Zn}^{2+}$ e $\mathrm{Co}^{2+}$ são crescentes até $15 \mathrm{~h}$, decrescendo até $20 \mathrm{~h}$, em virtude da saturação do adsorbato, evidenciando o processo de dessorção. Em seguida, o sistema atinge o equilíbrio, caracterizando a adsorção real dos metais no vermicomposto.

Já no caso do cobre o equilíbrio é alcançado em torno de $20 \mathrm{~h}$. Perfis similares, mas com tempos diferentes, foram encontrados em estudo envolvendo a adsorção de cobre em latossolos com alto teor de matéria orgânica ${ }^{19}$. Estes perfis de adsorção em função do tempo podem ser usados em eventuais estudos de descontaminação de águas por metais.

É importante ressaltar que a escassez de dados publicados referentes à concentração de metais em vermicompostos dificulta a comparação com os dados obtidos neste trabalho. Nos poucos trabalhos publicados foi constatado que o vermicomposto se assemelha estruturalmente ao solo. Isso justifica as comparações feitas com solos neste trabalho.

Para este estudo obteve-se a seguinte ordem na capacidade de adsorção pelo vermicomposto: $\mathrm{Cu}^{2+}>\mathrm{Zn}^{2+}>\mathrm{Co}^{2+}$.

\section{CONCLUSÃO}

Os metais contidos nos vermicompostos não apresentaram concentrações que pudessem sugerir problemas de contaminação ambiental, caso usados como adubos. Os resultados sugerem que os vermicompostos em estudo possuem ação corretiva da acidez $(\mathrm{pH}$ em torno de 7) e contém macro e micronutrientes, principalmente $\mathrm{Ca}, \mathrm{Mg}, \mathrm{K}, \mathrm{S}$, Cu e Zn.

Foi observado que o pH e o tempo são importantes no controle da adsorção de metais em vermicomposto. Para este estudo a quantidade de metal adsorvido encontra-se na ordem $\mathrm{Cu}^{2+}>\mathrm{Zn}^{2+}>\mathrm{Co}^{2+}$.

A termogravimetria mostrou-se uma técnica útil na determinação simultânea da umidade, teor de matéria orgânica e cinzas, sob atmosfera dinâmica de ar. Sob nitrogênio, a queima da matéria orgânica é incompleta. Já a digestão da amostra em forno de microondas foi bastante satisfatória, após a otimização do programa de aquecimento e a solução digestora, demonstrando ser um processo rápido, eficiente e seguro.

\section{AGRADECIMENTOS}

Os autores agradecem ao CNPq pelas bolsas e ao Prof. Dr. J. de A. Nóbrega (DQ-UFSCar), pelo uso do digestor de microondas e sugestões.

\section{REFERÊNCIAS}

1. Senesi, N.; D’Orazio, V.; Miamo, T. M.; Geoderma 1995, 66, 273.

2. Senesi, N.; Sci. Total Environ. 1989, 81/82, 521.

3. Landgraf, M. D.; Alves, M. R.; Silva S. C. E.; Rezende, M. O. O.; Quim. Nova 1999, 22, 483 .

4. Santos, J. A., coord; Manuais práticos: vida de minhocas, Ed. Três: São Paulo, 1986.

5. Lamim, S. S. M.; Jordão, C. P.; Brune, W.; Pereira, J. L.; Bellato, C. R.; Quim. Nova 1998, 21, 278.

6. Sanchez, I.; Lee, G. F.; Water Res. 1973, 7, 587.

7. Silva, F. C.; Boaretto, A. E.; Berton, R. S.; Zoteli, H. B.; Pexe, C. A.; Mendonça, E.; PAB - Pesquisa Agropecuária Brasileira 1998, 33, 414.

8. Kiehl, E. J.; Fertilizantes orgânicos, Ed. Agronômica Ceres: Piracicaba, 1985.

9. Landgraf, M. D.; Tese de Doutorado, Universidade de São Paulo, Brasil, 1996.

10. Malavolta, E.; Elementos de nutrição de plantas, Ed. Agronômica Ceres: Piracicaba, 1980.

11. Malavolta, E.; Fertilizantes e seu impacto ambiental: metais pesados, mitos, mistificação e fato, Produquímica: São Paulo, 1994.

12. Krug, F. J.; Métodos de decomposição de amostra, III Work Shopping, Universidade Federal de São Carlos, 2000.

13. Brown, M. E.; Introduction to thermal analysis: tecniques and applications, Chapman \& Hall: London, 1988.

14. Wendlandt, W. WM.; Thermal analysis, $3^{\text {rd }}$ ed., John Willey: New York, 1986.

15. Reis, B. F.; Zagatto, E. A. G.; Jacintho, A. O; Krug, F. J.; Bergamin, H.; Anal. Chim. Acta 1980, 119, 305.

16. Tsai, S. M.; Tablas, M.; Minhocultura 2000 - Tecnologia e Aplicações. Minhocultura, Green Seal: Piracicaba, 2000.

17. Jordão, C. P.; Alves, N. M.; Pereira, J. L.; Bellato, C. R.; Alvarez, V. H.; Quim. Nova 2000, 23, 5.

18. Cottenie, A.; International conference on heavy metals in the environment, Edinburgo, Escócia, 1981.

19. Pepin, R. G.; Coleman, P.; BioCycle 1984, 25, 52.

20. Pereira, M. G.; Arruda, M. A. Z.; J. Braz. Chem. Soc. 2003, 14, 39.

21. Soares, J. P.; Dissertação de Mestrado, Universidade Federal do Maranhão, Brasil, 2000.

22. Bard, A.J.; Equilíbrio Químico, Harper \& Row: New York, 1970. 